\title{
DISCRETE-TIME SLIDING MODE DIRECT POWER CONTROL FOR THREE- PHASE RECTIFIERS
}

\author{
Francisco Neves*, Roberto Dias Filho*, Felipe Camboim*, Marcelo Cavalcanti", Emilio Bueno** \\ *Grupo de Eletrônica de Potência e Acionamentos Elétricos - GEPAE \\ Universidade Federal de Pernambuco - Recife - PE - Brasil \\ fneves@ufpe.br,diasrob@gmail.com, felipecamboim@yahoo.com.br,marcelo.cavalcanti@ufpe.br \\ ${ }^{* *}$ Departamento de Electrónica \\ Universidad Alcalá de Henares - Alcalá de Henares - Madrid - España \\ emilio@depeca.uah.es
}

\begin{abstract}
In this paper a new discrete-time sliding mode control scheme for three-phase PWM rectifiers is proposed. Active and reactive powers are directly controlled using a virtual-flux oriented reference frame. Robustness of the proposed methodology under inductance variation is shown. Simulation results of a rectifier connected to a large power system are presented to compare the proposed strategy and the voltage oriented control scheme. Experimental results also show the better performance of the proposed scheme.
\end{abstract}

Keywords - Discrete-time sliding mode control, threephase rectifiers, virtual-flux oriented control, voltage oriented control.

\section{INTRODUCTION}

The amount of loads that are connected to the source by some kind of power electronic converter greatly increased in the last decades. Most of these converters include a rectifier input stage, forcing researchers to study and develop rectifiers in compliance with stringent requisites (e.g. IEEE 519, IEC61000) in terms of input currents harmonic distortion, input power factor and efficiency. Many researchers have investigated the use of conventional threephase diode rectifiers to which some power electronic circuit is added for achieving low input currents harmonic distortion and high power factor [1]-[6]. Applications such as ac/dc/ac variable speed drives and dc distributed power systems require the use of a forced commutated converter at the front end, instead of a simple diode or a phase commutated rectifier. This is due to the necessity of bidirectional power flow in some applications, such as ac/dc/ac converters for grid connected wind turbines. The three-phase boost rectifier, shown in Figure 1, has been the most popular topology.

Various control methods have been proposed in the latest years on this type of rectifier. Specially, the voltage oriented control (VOC) has been often applied [7] and [8]. Its dynamic response is mainly related with the technique utilized for synchronization with the grid voltage, which might be strongly susceptible to unbalance and harmonics present in the grid voltages, and the quality of the internal current control loops.

Manuscript received on 12/11/2009. Revised on 21/03/2010. Accepted for publication on 11/04/2010 by recommendation of the Editor Fernando L. M. Antunes.

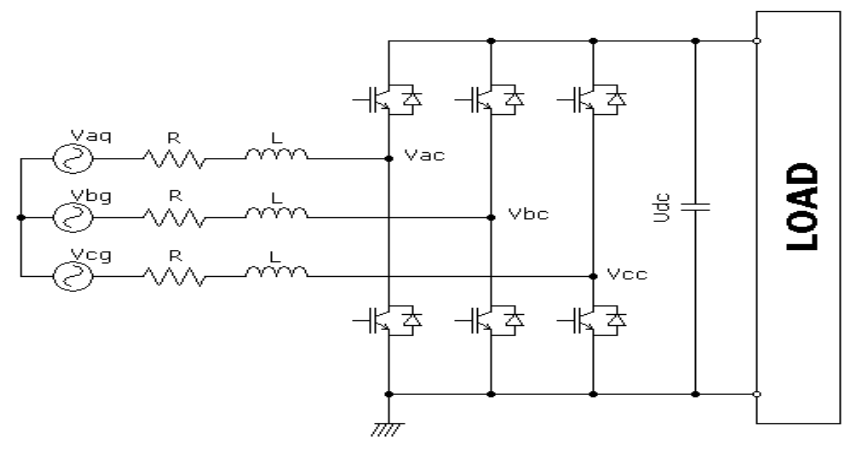

Fig. 1. Three-phase boost rectifier.

Representing an alternative to the VOC scheme is the voltage oriented direct power control (DPC), developed in [9] and [10]. It does not need the internal current control loops, but grid voltage unbalance and harmonics can again deteriorate the performance of the system.

In order to reduce the grid voltages influence on the current waveforms, the virtual-flux oriented direct power control (VF-DPC) was proposed [11]. The integrators used for obtaining the virtual-flux attenuate the $\mathrm{n}^{\text {th }}$ harmonic component contained in the grid voltage waveform by $1 / \mathrm{n}$. Both DPC and VF-DPC use hysteresis comparators and switching tables for determining the converter voltage vector to be applied, which makes the switching frequency vary causing high order harmonics in the current. Another major drawback of these schemes is the need for high sampling frequency thus requiring fast microprocessor and $\mathrm{A} / \mathrm{D}$ converters [12]. The main advantages of the VF-DPC are its robustness and fast dynamic response.

The problem with the variable frequency in VF-DPC was overcome by substituting the hysteresis comparators and the switching table by proportional-integral (PI) controllers in [12] and [13]. The outputs of the PIs are the direct and quadrature voltage components that must be synthesized by the converter. This is accomplished through a space vector modulator. In another proposal the PIs give place to a deadbeat controller [14] and [15]. Again, space vector modulation is used for producing the desired converter voltage vector. These two methods are known in the literature as SVM-DPC and deadbeat-DPC, respectively.

The main purpose of this paper is to present a new discrete-time sliding mode direct power control (SM-DPC) scheme. In this scheme, sliding mode control theory is used 
to determine the voltage components, and once again a space vector modulator is employed to attain the reference voltage vector. The proposed method has many interesting features:

- Fast dynamic response;

- Low sensitivity to grid voltages unbalance or harmonics;

- Nearly sinusoidal current waveform;

- Constant switching frequency;

- Low sampling frequency;

- No voltage sensors are required;

- Robustness to filter parameter variations.

\section{SLIDING-MODE DIRECT POWER CONTROL}

Considering the three-phase rectifier shown in Figure 1, the grid voltage vector in an arbitrary $d q$ reference frame is:

$$
\vec{v}_{d q g}=R \vec{\imath}_{d q}+L d\left(\vec{\imath}_{d q}\right) / d t+j \omega_{a} L \vec{\imath}_{d q}+\vec{v}_{d q c},
$$

where $\vec{v}_{d q g}$ and $\vec{v}_{d q c}$ are the grid and converter voltage vectors; $\vec{l}_{d q}$ is the filter inductor current vector and $\omega_{a}$ is the arbitrary angular speed of the $d q$ reference frames. The instantaneous active and reactive powers can be written in terms of the grid voltage and filter current $d$ and $q$ components:

$$
\left\{\begin{array}{l}
p=(3 / 2) \operatorname{Re}\left\{\vec{v}_{d q g} \vec{\imath}_{d q}^{*}\right\}=(3 / 2)\left(v_{d g} i_{d}+v_{q g} i_{q}\right) \\
q=(3 / 2) \operatorname{Im}\left\{\vec{v}_{d q g} \vec{\imath}_{d q}^{*}\right\}=(3 / 2)\left(-v_{d g} i_{q}+v_{q g} i_{d}\right)
\end{array}\right.
$$

The proposed sliding-mode direct power control is based on the real and reactive power dynamic equations, written in terms of the virtual-flux. In the stationary $\alpha \beta$ reference frame, the virtual-flux vector is obtained from:

$$
d\left(\vec{\lambda}_{\alpha \beta g}\right) / d t=\vec{v}_{\alpha \beta g} .
$$

Thus, in an arbitrarily rotating $d q$ reference frame, the grid voltage vector written in terms of the virtual-flux vector is equal to:

$$
\vec{v}_{d q g}=d\left(\vec{\lambda}_{d q g}\right) / d t+j \omega_{a} \vec{\lambda}_{d q g}
$$

therefore the active and reactive powers in terms of the virtual-flux are

$$
\left\{\begin{array}{l}
p=(3 / 2)\left[\frac{d \lambda_{d g}}{d t} i_{d}+\frac{d \lambda_{q g}}{d t} i_{q}+\omega_{a}\left(\lambda_{d g} i_{q}-\lambda_{q g} i_{d}\right)\right] \\
q=(3 / 2)\left[\frac{d \lambda_{q g}}{d t} i_{d}-\frac{d \lambda_{d g}}{d t} i_{q}+\omega_{a}\left(\lambda_{d g} i_{d}+\lambda_{q g} i_{q}\right)\right]
\end{array}\right.
$$

If a virtual-flux vector oriented $d q$ reference frame is used, and assuming that the virtual-flux vector amplitude oscillations are negligible, then the active and reactive power components become:

$$
\left\{\begin{array}{l}
p=(3 / 2) \omega \lambda i_{q} \\
q=(3 / 2) \omega \lambda i_{d}
\end{array}\right.
$$

where $\omega$ is the virtual-flux vector angular speed (or the synchronous speed) and $\lambda$ is the virtual-flux vector magnitude. Rewriting (4) with the reference frame oriented by the virtual-flux vector and substituting it together with (6) into (1) gives:

$$
\left\{\begin{array}{l}
v_{d g}=\frac{d \lambda_{d g}}{d t}-\omega \lambda_{q g} \cong 0=\frac{2 L}{3 \omega \lambda} \frac{d}{d t} q-\frac{2 L}{3 \lambda} p+v_{d c} \\
v_{q g}=\frac{d \lambda_{q g}}{d t}+\omega \lambda_{d g}=\omega \lambda=\frac{2 L}{3 \omega \lambda} \frac{d}{d t} p+\frac{2 L}{3 \lambda} q+v_{q c}
\end{array}\right.
$$

The dynamic equations for the active and reactive power components can be written in terms of the virtual-flux vector components by rearranging (7):

$$
\left\{\begin{array}{l}
\frac{d}{d t} q=\omega p-\frac{3 \omega \lambda}{2 L} v_{d c} \\
\frac{d}{d t} p=-\omega q-\frac{3 \omega \lambda}{2 L}\left(v_{q c}-\omega \lambda\right)
\end{array} .\right.
$$

Discrete-time versions of (8) may be obtained by using difference equations for substituting the derivatives, resulting in:

$$
\left\{\begin{array}{l}
q_{k+1}=q_{k}+\omega h_{s} p_{k}-\frac{3 \omega \lambda_{k}}{2 L} h_{s} v_{d c k} \\
p_{k+1}=p_{k}-\omega h_{s} q_{k}-\frac{3 \omega \lambda_{k}}{2 L} h_{s}\left(v_{q c k}-\omega \lambda_{k}\right)
\end{array} .\right.
$$

The converter voltage components $\mathrm{v}_{\mathrm{dck}}$ and $\mathrm{v}_{\mathrm{qck}}$ for deadbeat real and reactive power control could be obtained from (8) simply forcing $\mathrm{p}_{\mathrm{k}+1}=\mathrm{p}^{*}$ and $\mathrm{q}_{\mathrm{k}+1}=\mathrm{q}^{*}$. The cross coupling terms, i.e., the second right-hand term of each equation in (9), as well as the last term $\left(3 \omega^{2} \lambda_{\mathrm{k}}^{2} \mathrm{~h}_{\mathrm{s}} / 2 \mathrm{~L}\right)$ of the equation for $p_{k+1}$, could be considered as known disturbances, since they could be estimated from the measured currents and estimated virtual flux components. The result would be a fast and precise control scheme with a constant switching frequency. However, as in any deadbeat control, the strategy would be very sensitive to measuring errors, parameter variations or virtual flux estimation errors. For this reason, a sliding mode control scheme is designed in order to ensure the control's robustness [16].

Let $\mathrm{x}_{\mathrm{q}}$ and $\mathrm{x}_{\mathrm{d}}$ be the reactive and active power errors, respectively:

$$
\left\{\begin{array}{l}
x_{q}=q^{*}-q ; \frac{d}{d t} x_{q}=-\omega p+\frac{3 \omega \lambda}{2 L} v_{d c} \\
x_{p}=p^{*}-p ; \frac{d}{d t} x_{p}=\omega q+\frac{3 \omega \lambda}{2 L}\left(v_{q c}-\omega \lambda\right)
\end{array},\right.
$$

or, in discrete-time domain:

$$
\left\{\begin{array}{l}
x_{q_{k+1}}=x_{q_{k}}-\omega h_{s} p_{k}+\frac{3 \omega \lambda_{k}}{2 L} h_{s} v_{d c_{k}} \\
x_{p_{k+1}}=x_{p_{k}}+\omega h_{s} q_{k}+\frac{3 \omega \lambda_{k}}{2 L} h_{s}\left(v_{q c_{k}}-\omega \lambda_{k}\right)
\end{array}\right.
$$

Consider that the chosen sliding surfaces are equal to the system errors: $\mathrm{S}_{\mathrm{qk}}=\mathrm{x}_{\mathrm{q}_{\mathrm{k}}}=0$ and $\mathrm{S}_{\mathrm{dk}}=\mathrm{x}_{\mathrm{p}_{\mathrm{k}}}=0$. In discrete-time sliding-mode control systems, it is desirable to choose the system inputs $\left(\mathrm{v}_{\mathrm{dc}_{\mathrm{k}}}\right.$ and $\left.\mathrm{v}_{\mathrm{qc}_{\mathrm{k}}}\right)$ so that three conditions are met [16]:

- The switching functions $\left(\mathrm{S}_{\mathrm{q}}=0\right.$ and $\left.\mathrm{S}_{\mathrm{d}}=0\right)$ must be crossed in a finite number of sampling intervals;

- After being crossed for the first time, the switching function should be crossed again each sampling interval;

- After a switching function is crossed for the first time, the corresponding value of $\left|S_{k}\right|$ remains smaller than a certain specified limit.

It can be verified that the three mentioned conditions are satisfied if

$$
S_{k+1}-S_{k}=-\alpha h_{s} S_{k}-\beta h_{s} \operatorname{sgn}\left\{S_{k}\right\},
$$

where $\alpha>0, \beta>0,\left(1-\alpha h_{s}\right)>0$. In fact, it can be easily 
seen that whenever $S_{k}>0$, then $S_{k+1}-S_{k}<-\beta h_{s}$; and whenever $S_{k}<0$, then $S_{k+1}-S_{k}>\beta h_{s}$, which ensures the first condition to hold. Further, when $S_{k}$ is near the switching surface, i.e., when $-\beta h_{s}<S_{k}<\beta h_{s}$, then the two other conditions are satisfied. This can be easily shown as follows. If $S_{k}=\gamma \beta h_{s}, 0<\gamma<1$, then condition (12) imposes that

$$
S_{k+1}=-\left[1-\left(1-\alpha h_{s}\right) \gamma\right] \beta h_{s}
$$

and since $0<\left(1-\alpha h_{s}\right)<1$ and $0<\gamma<1$ :

$$
-\beta h_{s}<S_{k+1}<0 \text {. }
$$

Analogously, if $S_{k}=-\gamma \beta h_{s}$, it is easily verified that

$$
0<S_{k+1}<\beta h_{s} \text {. }
$$

The next step consists of finding the converter $d$ and $q$ voltage components in order to guarantee that equation (12) is satisfied. Remembering that $\mathrm{S}_{\mathrm{q}_{\mathrm{k}}}=\mathrm{x}_{\mathrm{q}_{\mathrm{k}}}$ and $\mathrm{S}_{\mathrm{d}_{\mathrm{k}}}=\mathrm{x}_{\mathrm{d}_{\mathrm{k}}}$, and substituting (11) in (12), these voltage components are determined:

$$
\left\{\begin{array}{l}
v_{d c_{k}}=\frac{2 L}{3 \omega \lambda_{k}}\left(-\alpha x_{q k}-\beta \operatorname{sgn}\left\{x_{q k}\right\}\right)+\frac{2 L}{3 \lambda_{k}} p_{k} \\
v_{q c_{k}}=\frac{2 L}{3 \omega \lambda_{k}}\left(-\alpha x_{d k}-\beta \operatorname{sgn}\left\{x_{d k}\right\}\right)-\frac{2 L}{3 \lambda_{k}} q_{k}+\omega \lambda_{k}
\end{array} .\right.
$$

It should be noted that if $\alpha h_{s}=1$ and $\beta h_{s}=0$, then the control law for deadbeat control is achieved. It is expected that if parameter $\alpha$ is close to one, then the dynamic response wil be very fast, comparable with the deadbeat response. Also, if parameter $\beta$ is near to zero, than the error oscillations around zero are expected to have low amplitude. On the other hand, in these cases the control system would be more sensitive to parameter variations and external disturbances.

\section{CONTROL LAW FOR ENSURING ROBUSTNESS}

Taking into account parameter deviations and external disturbances, a discrete-time system dynamic equation can be written in the following form:

$$
x_{k+1}=A x_{k}+\Delta A x_{k}+b u_{k}+f_{k} \text {, }
$$

where $\Delta A=b \tilde{A}$ is used for taking into account parameter deviations in the state matrix $A$ and $f_{k}=b \tilde{f}_{k}$ represents external disturbances.

In order to ensure that the three mentioned conditions are attained even in the presence of external disturbances or parameter deviations, the discrete-time system dynamic equations will be written in the following form:

$$
x_{k+1}=A x_{k}+b\left(u_{k}+\tilde{A} x_{k}+\tilde{f}_{k}\right) \text {. }
$$

Since $\widetilde{\mathrm{A}}$ and $\tilde{\mathrm{f}}_{\mathrm{k}}$ are unknown, they cannot be compensated through feedforward terms. However, the maximum expected parameter deviations and external disturbances may be used for determining a conservative control law which ensure two conditions to hold: a) convergence to the switching surface in a finite number of sampling periods; b) after the switching surface is reached, the distance to it surface will remain limited to some specified value. These two conditions may be imposed by defining a new approaching law, slightly different from (12):

$S_{k+1}-S_{k}=-\alpha h_{S} S_{k}-\beta h_{s} \operatorname{sgn}\left\{S_{k}\right\}+\tilde{S}_{A_{k}}-S_{A C}+\tilde{S}_{f_{k}}-S_{f C}$, where

and

$$
\left\{\begin{array}{l}
S_{A L} \leq \tilde{S}_{A k}=b \tilde{A} x_{k} \leq S_{A U} \\
S_{f L} \leq \tilde{S}_{f k}=b \tilde{f}_{k} \leq S_{f U}
\end{array}\right.
$$

$$
\left\{\begin{array}{l}
\text { if } S_{k} \geq 0,\left(S_{A C}=S_{A U} ; S_{f C}=S_{f U}\right) \\
\text { if } S_{k}<0,\left(S_{A C}=S_{A L} ; S_{f C}=S_{f L}\right)
\end{array}\right.
$$

It can be easily demonstrated that condition (19) ensures that if $S_{k}>0$, then $S_{k+1}<S_{k}-\beta h_{s}$; and if $S_{k}<0$, then $S_{k+1}>S_{k}+\beta h_{s}$. This ensures that the sliding surface will be crossed in a finite number of sampling time intervals.

Further, when $S_{k}$ is near to zero, i.e., $\left|S_{k}\right|<\beta h_{s}$, its absolute value will be confined to the following neighborhood:

$$
\left|S_{k+1}\right|<\left[\beta h_{s}+\left(S_{A U}-S_{A L}\right)+\left(S_{f U}-S_{f L}\right)\right] .
$$

To demonstrate the condition in (22) is also straightforward. If $S_{\mathrm{k}}=\gamma \beta \mathrm{h}_{\mathrm{s}}, 0<\gamma<1$, then (19) imposes that

$$
\left[-\beta h_{s}-\left(S_{A U}-S_{A L}\right)-\left(S_{f U}-S_{f L}\right)\right]<S_{k+1}<0 .
$$

On the other hand, if $S_{k}=-\gamma \beta h_{s}, 0<\gamma<1$, then

$$
0<S_{k+1}<\left[\beta h_{s}+\left(S_{A U}-S_{A L}\right)+\left(S_{f U}-S_{f L}\right)\right] \text {. }
$$

It is evident from (23) and (24) that the more robustness to be added to the control, the wider the neighborhood around the switching function and, consequently, larger active and reactive power error oscillations around zero are expected.

\section{A. Control Law for robustness to filter parameter variations}

Consider that due to saturation, the filter inductance can experiment variations around its rated value $\hat{\mathrm{L}}$ :

$$
0.7 \hat{L}<L<1.1 \hat{L} \text {. }
$$

Based on this possibility, the discrete-time dynamic equations of active and reactive power errors can be rewritten as:

$$
\left\{\begin{array}{l}
x_{q_{k+1}}=x_{q_{k}}-\omega h_{s} p_{k}+(\hat{b}+\Delta b) v_{d c_{k}} \\
x_{p_{k+1}}=x_{p_{k}}+\omega h_{s} q_{k}+(\hat{b}+\Delta b)\left(v_{q c_{k}}-\omega \lambda_{k}\right)
\end{array}\right.
$$

where $\Delta b$ is used to take into account the possible variations in the filter inductance:

$$
\hat{b}+\Delta b=\frac{3 \omega \lambda_{k}}{2(\hat{L}+\Delta L)} h_{s},
$$

or, in order to explicit the terms corresponding to the uncertainties:

$$
\left\{\begin{array}{l}
x_{q_{k+1}}=x_{q_{k}}-\omega h_{s} p_{k}+\hat{b} v_{d c_{k}}+\hat{b} \tilde{f}_{q_{k}} \\
x_{p_{k+1}}=x_{p_{k}}+\omega h_{s} q_{k}+\hat{b}\left(v_{q c_{k}}-\omega \lambda_{k}\right)+\hat{b} \tilde{f}_{p_{k}}
\end{array},\right.
$$

where

$$
\left\{\begin{array}{l}
\tilde{f}_{q_{k}}=\frac{\Delta b}{\hat{b}} v_{d c_{k}} \\
\tilde{f}_{p_{k}}=\frac{\Delta b}{\hat{b}}\left(v_{q c_{k}}-\omega \lambda_{k}\right)
\end{array} .\right.
$$

Recalling that the chosen sliding surfaces are the active and reactive power errors and imposing approaching law (19), the robust control laws can be determined:

$$
\left\{\begin{array}{l}
v_{d c_{k}}=\frac{h_{s}}{\hat{b}}\left(-\alpha x_{q k}-\beta \operatorname{sgn}\left\{x_{q k}\right\}+\omega p_{k}\right)-f_{q C} \\
v_{q c_{k}}=\frac{h_{s}}{\hat{b}}\left(-\alpha x_{p k}-\beta \operatorname{sgn}\left\{x_{p k}\right\}-\omega q_{k}\right)+\omega \lambda_{k}-f_{p C}
\end{array}\right.
$$

where

$$
\left\{\begin{array} { l } 
{ \text { if } x _ { q _ { k } } \geq 0 , f _ { q _ { C } } = \tilde { f } _ { q _ { \operatorname { m a x } } } } \\
{ \text { if } x _ { q _ { k } } < 0 , f _ { q _ { C } } = \tilde { f } _ { q _ { \operatorname { m i n } } } }
\end{array} \text { and } \left\{\begin{array}{l}
\text { if } x_{p_{k}} \geq 0, f_{p_{C}}=\tilde{f}_{p_{\max }} \\
\text { if } x_{p_{k}}<0, f_{p_{C}}=\tilde{f}_{p_{\min }}
\end{array}\right.\right.
$$

For determining the maximum and minimum values of $\tilde{\mathrm{f}}_{\mathrm{q}}$ and $\tilde{f}_{\mathrm{p}}$, the signals of $\mathrm{v}_{\mathrm{dc}_{\mathrm{k}}}$ and $\left(\mathrm{v}_{\mathrm{qc}}-\omega \lambda_{\mathrm{k}}\right)$ are necessary. In order to examine these signals, Table I and Table II present all the possibilities.

Thus, as it can be observed in Table I and Table II, the sign of $\mathrm{v}_{\mathrm{dc}_{\mathrm{k}}}$ is always equal to that of $\left(-\alpha \mathrm{x}_{\mathrm{qk}}-\right.$ $\left.\beta \operatorname{sgn}\left\{\mathrm{x}_{\mathrm{qk}}\right\}+\omega \mathrm{p}_{\mathrm{k}}\right)$ and the sign of $\left(\mathrm{v}_{\mathrm{qc}_{\mathrm{k}}}-\omega \lambda_{\mathrm{k}}\right)$ is equal to 
the sign of $\left(-\alpha x_{p k}-\beta \operatorname{sgn}\left\{x_{p k}\right\}-\omega q_{k}\right)$. The desired robust control laws can then be easily determined using the algorithms shown in Table III.

\section{SIMULATION RESULTS}

\section{A. Rectifier Connected to an Infinite Busbar}

The circuit shown in Figure 1 with a simple resistive load was simulated in Matlab using a conventional VOC scheme and the proposed SM-DPC. The simulated system data are given in Table IV. A Syncronous Reference Frame PhaseLocked Loop -SRF-PLL [17] was used in the VOC system for synchronization.

The simulations were performed in order to illustrate the characteristics of the proposed methodology in comparison with the conventional VOC scheme. Distorted grid voltages were considered, by adding $5 \%$ of $5^{\text {th }}$ to the phase signals.

Figure 2 shows the phase $a$ grid voltage and the respective L-filter current obtained when applying the traditional VOC with PLL. The current total harmonic distortion (THD) is $7.84 \%$. As expected, the voltage waveform influences the filter current harmonic content.

The SRF-PLL fails to extract the fundamental component of the grid voltage [18], thus making the grid voltage vector amplitude and angle oscillate. This information is essential for the correct operation of the VOC control scheme.

In the virtual flux oriented direct power control, the voltage distortions are expected to be somewhat filtered, since the flux components are obtained by integrating the grid voltage $\alpha$ and $\beta$ components.

In practice, eventual offsets in the measured voltages would cause instability if pure integrators were used to estimate the virtual flux. To avoid such problem, a low-pass filter cascaded with a high-pass filter has been employed for this task. Both are first order filters with cut-off frequency equal to $5 \mathrm{~Hz}$. The output of the cascaded filters has its gain and phase corrected for the grid frequency, so that it behaves like an ideal integrator at the fundamental frequency.

The phase $a$ grid voltage and filter current obtained when applying the proposed SM-DPC scheme are shown in Figure 3. A more sinusoidal current waveform is now obtained. The phase $a$ current THD using the SV-DPC was reduced to $6.01 \%$. The low order harmonics are considerably reduced. The higher order harmonics are larger, due to the design procedure, in which robustness to variations in the filter inductance was considered.

The oscillations in the active and reactive power components are also reduced when using the proposed DPC scheme, as it can be observed in Figures 4 and 5.

\section{B. Rectifier Connected to a Real Power System}

Some new simulations focusing the performance of the rectifier when connected to a large electrical network are presented to highlight the benefits of the proposed SM-DPC. This is carried out by connecting the rectifier directly to a real power system network, unlike an infinite busbar, as widely adopted in similar studies. Representing in details the electrical network allows the simulation of phenomena associated to switching, saturation, hysteresis and other nonlinearities, inherent to the daily events which take place in electrical power systems. Riding through these abnormal conditions requires, from the rectifier control system, capacity to reject noise and to keep the main characteristics of the electrical signals acquired by the control algorithm. Due to the bad responses obtained when using an SRF-PLL for the dq reference frame orientation in the VOC scheme, a DSOGI-PLL [19] was used instead.

TABLE I

Possible Values of $\mathbf{v}_{\mathbf{d c}}$

\begin{tabular}{cccc}
\hline$x_{q_{k}}$ & $v_{d c_{k}}$ & $f_{q_{c}}$ & $v_{d c_{k}}$ from $(30)$ \\
\hline$\geq 0$ & $\geq 0$ & $\frac{3 v_{d c_{k}}}{7}$ & $\frac{7}{10} \frac{h_{s}}{\hat{b}}\left(-\alpha x_{q k}-\beta+\omega p_{k}\right)$ \\
\hline$\geq 0$ & $<0$ & $-\frac{v_{d c_{k}}}{11}$ & $\frac{11}{10} \frac{h_{s}}{\hat{b}}\left(-\alpha x_{q k}-\beta+\omega p_{k}\right)$ \\
\hline$<0$ & $\geq 0$ & $-\frac{v_{d c_{k}}}{11}$ & $\frac{11}{10} \frac{h_{s}}{\hat{b}}\left(-\alpha x_{q k}+\beta+\omega p_{k}\right)$ \\
\hline$<0$ & $<0$ & $\frac{3 v_{d c_{k}}}{7}$ & $\frac{7}{10} \frac{h_{s}}{\hat{b}}\left(-\alpha x_{q k}+\beta+\omega p_{k}\right)$ \\
\hline
\end{tabular}

TABLE II

Possible Values of $\mathbf{v}_{\mathbf{q c}}$

\begin{tabular}{cccc}
\hline$x_{p_{k}}$ & $\left(v_{q c_{k}}-\omega \lambda_{k}\right)$ & $f_{p_{C}}$ & $\left(v_{q c_{k}}-\omega \lambda_{k}\right)$ from (30) \\
\hline$\geq 0$ & $\geq 0$ & $\frac{3\left(v_{q c_{k}}-\omega \lambda_{k}\right)}{7}$ & $\frac{7}{10} \frac{h_{s}}{\hat{b}}\left(-\alpha x_{q k}+\beta+\omega p_{k}\right)$ \\
\hline$\geq 0$ & $<0$ & $-\frac{\left(v_{q c_{k}}-\omega \lambda_{k}\right)}{11}$ & $\frac{11}{10} \frac{h_{s}}{\hat{b}}\left(-\alpha x_{p k}-\beta-\omega q_{k}\right)$ \\
\hline$<0$ & $\geq 0$ & $-\frac{\left(v_{q c_{k}}-\omega \lambda_{k}\right)}{11}$ & $\frac{11}{10} \frac{h_{s}}{\hat{b}}\left(-\alpha x_{p k}+\beta-\omega q_{k}\right)$ \\
\hline$<0$ & $<0$ & $\frac{3\left(v_{q c_{k}}-\omega \lambda_{k}\right)}{7}$ & $\frac{7}{10} \frac{h_{s}}{\hat{b}}\left(-\alpha x_{p k}+\beta-\omega q_{k}\right)$ \\
\hline
\end{tabular}

TABLE III

Robust Control Laws for 0. 7î̀ $<L<1.1 \hat{\mathbf{L}}$

\begin{tabular}{cc}
\hline \multicolumn{1}{c}{$v_{d c_{k}}$} & $v_{q c_{k}}$ \\
\hline if $\left(x_{q_{k}} \geq 0\right)$ & if $\left(x_{p_{k}} \geq 0\right)$ \\
$v_{a u x}=\left(-\alpha x_{q k}-\beta+\omega p_{k}\right)$ & $v_{a u x}=\left(-\alpha x_{p k}-\beta+\omega q_{k}\right)$ \\
if $\left(v_{a u x} \geq 0\right)$ & if $\left(v_{a u x} \geq 0\right)$ \\
$v_{d c_{k}}=7 h_{s} v_{a u x} /(10 \hat{b})$ & $v_{q c_{k}}=\omega \lambda_{k}+7 h_{s} v_{a u x} /(10 \hat{b})$ \\
else & else \\
$v_{d c_{k}}=11 h_{s} v_{a u x} /(10 \hat{b})$ & $\mathrm{v}_{\mathrm{qc}}=\omega \lambda_{\mathrm{k}}+11 \mathrm{~h}_{\mathrm{s}} \mathrm{v}_{\mathrm{aux}} /(10 \hat{\mathrm{b}})$ \\
end & end \\
else & else \\
$v_{a u x}=\left(-\alpha x_{q k}+\beta+\omega p_{k}\right)$ & $v_{a u x}=\left(-\alpha x_{p k}+\beta+\omega q_{k}\right)$ \\
if $\left(v_{a u x} \geq 0\right)$ & if $\left(\mathrm{v}_{\mathrm{aux}} \geq 0\right)$ \\
$v_{d c_{k}}=11 h_{s} v_{a u x} /(10 \hat{b})$ & $v_{q c_{k}}=\omega \lambda_{k}+11 h_{s} v_{a u x} /(10 \hat{b})$ \\
else & else \\
$v_{d c_{k}}=7 h_{s} v_{a u x} /(10 \hat{b})$ & en $v_{q c_{k}}=\omega \lambda_{k}+7 h_{s} v_{a u x} /(10 \hat{b})$ \\
end & end \\
end & end \\
\hline
\end{tabular}

TABLE IV

Circuit Parameters

\begin{tabular}{cc}
\hline Phase Voltage & $65 \mathrm{~V}_{\mathrm{RMS}}$ \\
\hline Voltage Frequency & $60 \mathrm{~Hz}$ \\
\hline Filter Resistance & $0.1 \Omega$ \\
\hline Filter Inductance & $9.6 \mathrm{mH}$ \\
\hline DC Bus Capacitor & $2350 \mu \mathrm{F}$ \\
\hline DC Bus Voltage Reference & $200 \mathrm{~V}$ \\
\hline Load Resistance & $242 \Omega$ \\
\hline Sampling Frequency & $20 \mathrm{kHz}$ \\
\hline Switching Frequency & $10 \mathrm{kHz}$
\end{tabular}




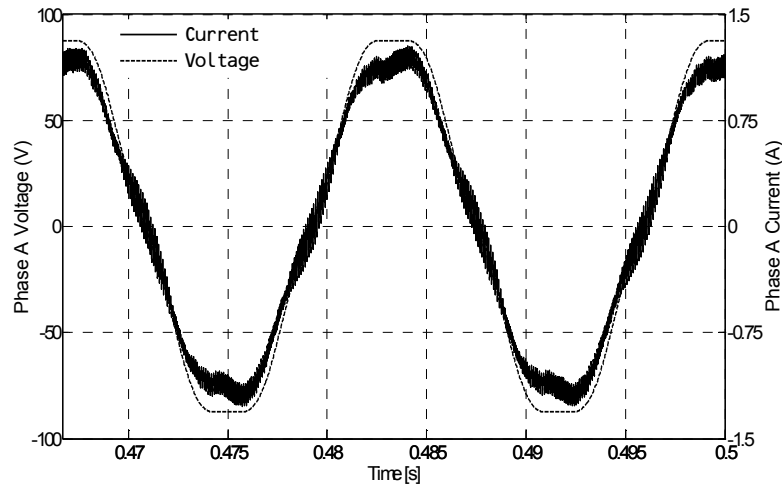

Fig. 2. Phase $a$ grid voltage and filter current obtained using the VOC scheme.

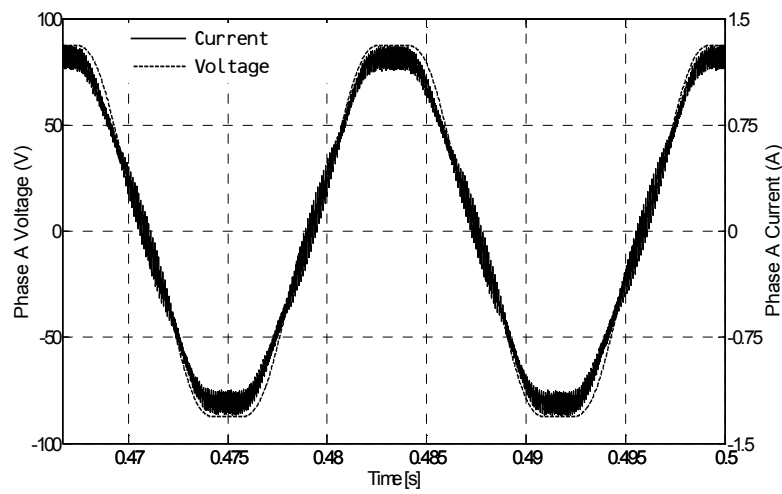

Fig. 3. Phase $a$ grid voltage and filter current obtained using the SM-DPC scheme.

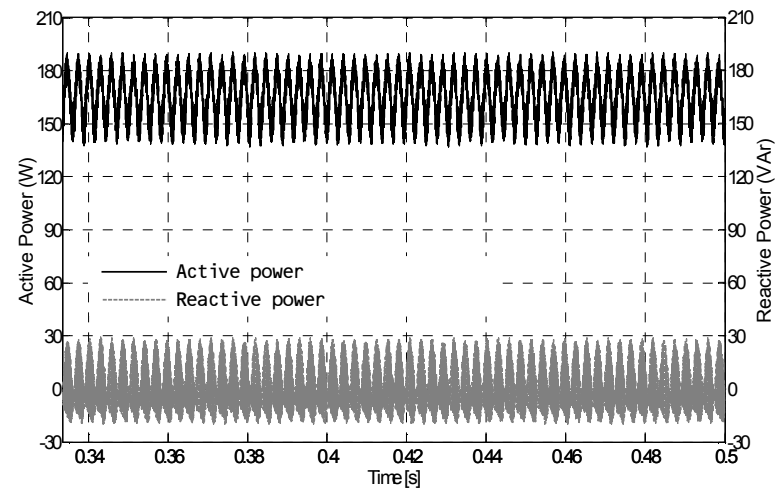

Fig. 4. Active and reactive power components for the VOC scheme.

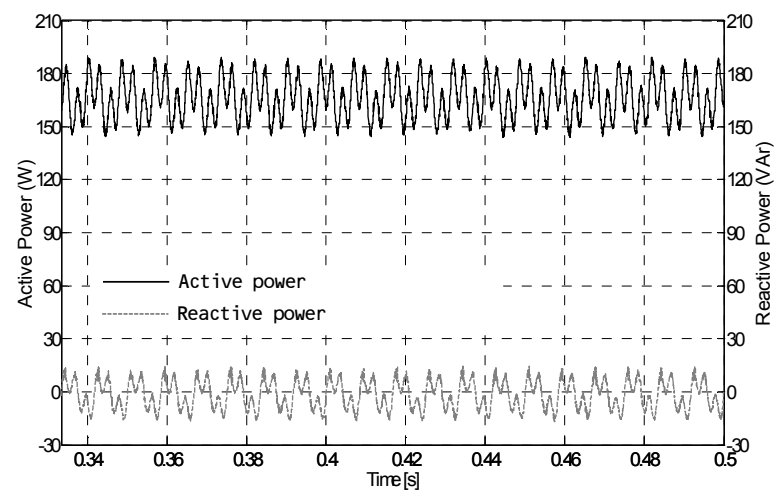

Fig. 5. Active and reactive power components for the SM-DPC scheme.
In order to achieve those simulation tasks, a computational tool known as Alternative Transient Program (ATP) is employed for modeling the electrical power system with the required accuracy for numerical simulations driven by computers. For example, in the present case the magnetizing characteristics of the power transformers and the transient models of electrical machines (synchronous compensators) are represented and models of long transmission lines are used. The simulated power system is shown if Figure 7, where the rectifier is indicated by VSC. Its parameters are presented in Table V.

The rectifier behavior is analyzed considering two types of disturbances:

- Disturbance Type 1: Phase-to-ground fault followed by reclosing of a transmission line

A phase-to-ground short-circuit is applied to a busbar in the vicinity of the rectifier. Further, two reclosing actions take place: one unsuccessful and the other successful. These events expose the two rectifier control techniques to severe unbalance, due to the shunt fault, and distorted environments, due to the electromagnetic transient phenomena associated to the reclosing.

- Disturbance Type 2: RL filter inductance deviation

A deviation from $-20 \%$ to $-50 \%$ is imposed to the RL filter inductance value by means of an application of a negative step to the inductance initially implemented on the electrical network. This reveals the sensitivity of each technique response to variations in the filter inductance.

TABLE V

Rectifier Parameters

\begin{tabular}{cc}
\hline Phase Voltage & $230 \mathrm{~V}_{\mathrm{RMS}}$ \\
\hline Voltage Frequency & $60 \mathrm{~Hz}$ \\
\hline Filter Resistance & $0.1 \Omega$ \\
\hline Filter Inductance & $10 \mathrm{mH}$ \\
\hline DC Bus Capacitor & $1000 \mu \mathrm{F}$ \\
\hline DC Bus Voltage Reference & $600 \mathrm{~V}$ \\
\hline Load Resistance & $100 \Omega$ \\
\hline Sampling Frequency & $20 \mathrm{kHz}$ \\
\hline Switching Frequency & $10 \mathrm{kHz}$
\end{tabular}

Figures 6, 8, 9 and 10 show graphically a comparison of these results.

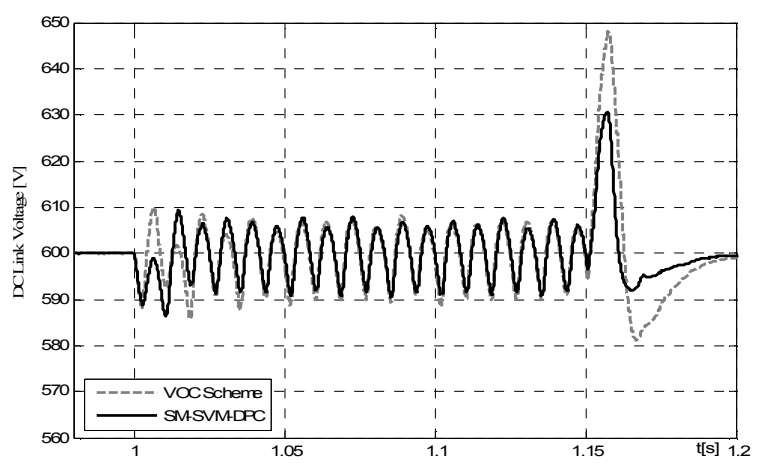

Fig. 6. DC link voltage after disturbance type 1. 


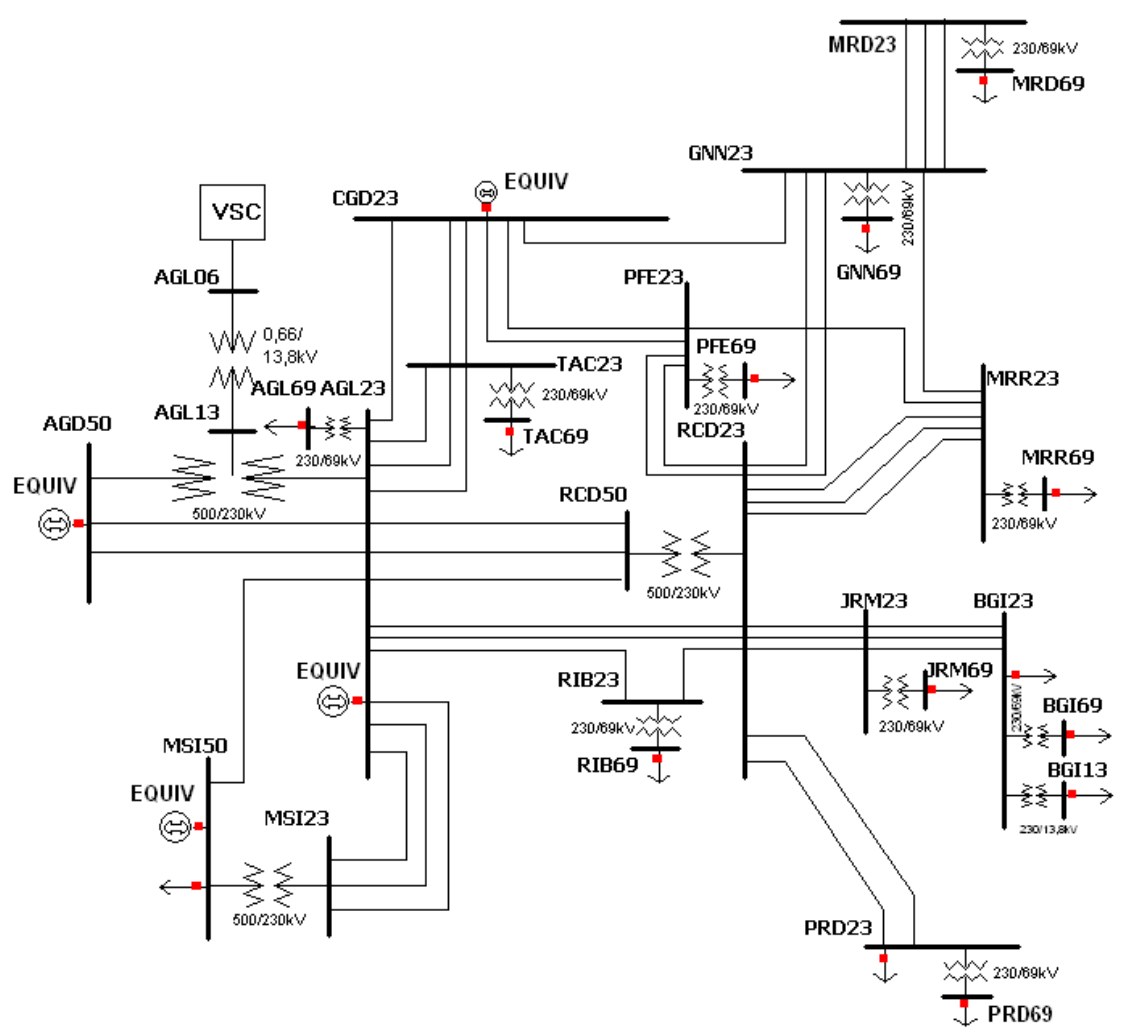

Fig. 7. Simulated power system to which the rectifier is connected.

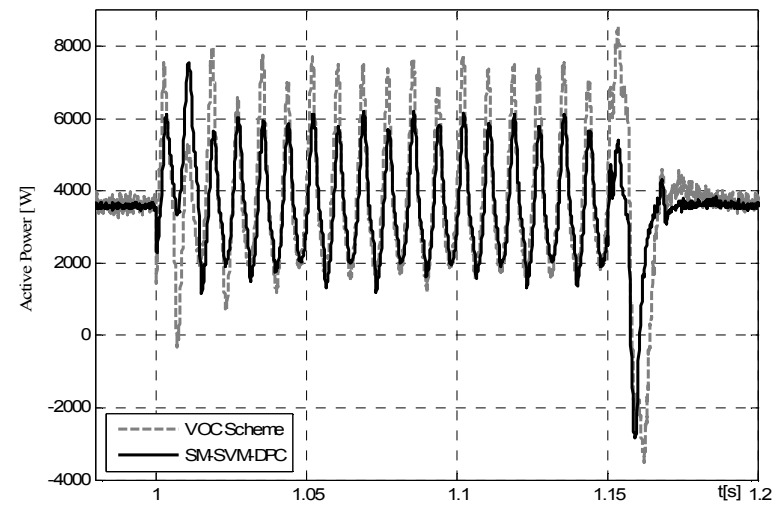

Fig. 8. Active power after disturbance type 1.

As it can be seen by the results exposed in Figures 6 and 8, the performance of the rectifier controlled by SM-DPC technique is better than the VOC scheme with respect to active power peak reduction. This reduction is an important question especially when controlling grid-converters used for driving wind generators, because power pulsation is associated to mechanical vibration, a situation that should be avoided. When comparing the DC link voltage, only a slight improvement is obtained with respect to the overshoot attenuation occurred when the disturbance is extinguished.

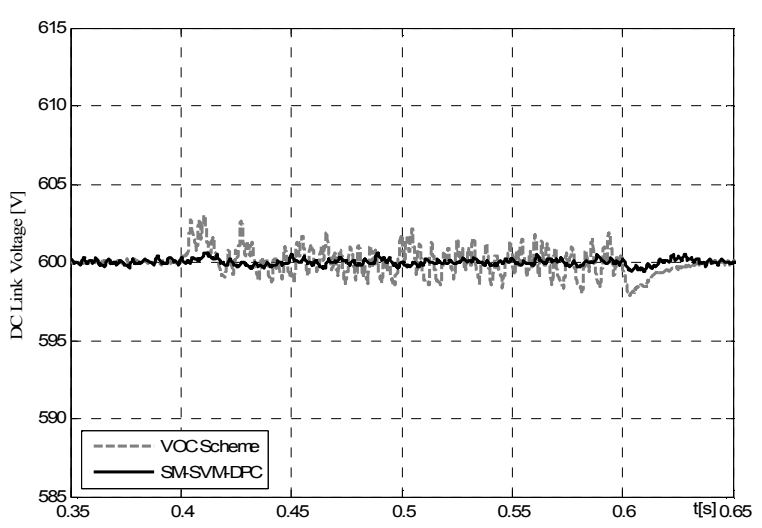

Fig. 9. DC link voltage after disturbance type 2.

It should be explained that the disturbance type 1 is very severe and it is hard to any technique to suppress the effects associated to such electromagnetic transients phenomena, SM-DPC rides through this abnormal conditions equally to VOC scheme in terms of THD\% of the filter current, in spite of being a more aggressive control technique than the current control adopted in most VOC schemes. Table VI presents a comparison of the currents THD\%. From the results shown in Figures 9 and 10, the better performance presented by the newer technique over the traditional VOC is evident. 


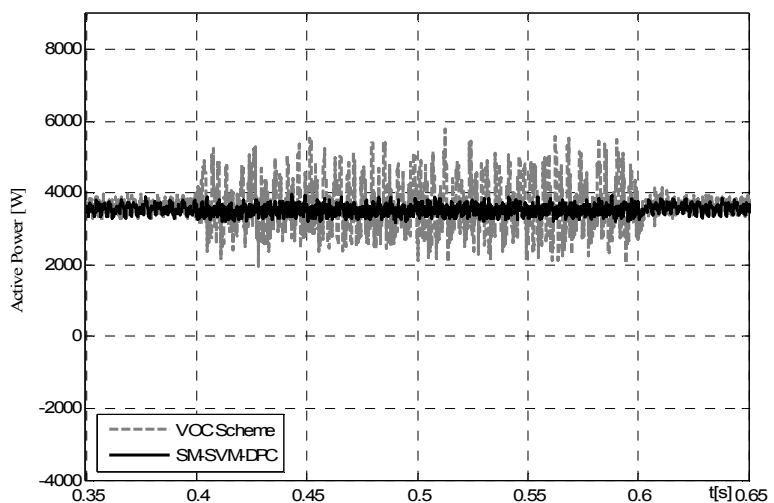

Fig. 10 Active power after disturbance type 2 .

TABLE VI

Filter Current THD\%

\begin{tabular}{lll}
\hline Technique & Disturbance type 1 & Disturbance type 2 \\
\hline VOC & 31.98 & 20.74 \\
\hline SM-DPC & 31.21 & 6.9 \\
\hline
\end{tabular}

The results show a capacity of the SM-DPC to reject parameter variation. This improvement was introduced by the sliding mode control applied. The disturbance applied corresponded to a reduction of $50 \%$ in the $\mathrm{RL}$ filter inductance with the rectifier now connected to a more realistic electrical network. When comparing the quality of filter currents, the benefits can be seen in Table VI: the currents when the VOC scheme is applied present a THD\% three times greater than that when the SM-DPC is used.

\section{EXPERIMENTAL RESULTS}

A prototype of the circuit shown in Figure 1 with the same parameters of Table IV was assembled for validating the proposed scheme. Both control algorithms were implemented digitally with a Texas Instruments TMS320F2812 fixed point digital signal processor.

As it can be observed in Figures 11 and 12, the voltage waveform in the laboratory is quite distorted. From a spectrum analysis it has been verified that the distortion is caused mainly by the fifth harmonic component. For this reason, this harmonic component was added to the fundamental voltage signals in the simulations in Matlab. As expected, the SM-DPC current waveform presents a much less distorted waveform. During the experiments, it was observed that the amplitude and frequency of the grid voltage vector detected by the SRF-PLL oscillated as expected, due to the voltage waveform distortions. These distortions were successfully attenuated by the digital filters used to compute the virtual flux vector, thus contributing to the better performance of the SM-DPC proposed technique.

\section{CONCLUSION}

A robust sliding mode control algorithm for direct power control of three-phase rectifiers was presented. The proposed technique has the advantages of good dynamic response, lower sensitivity to grid voltage unbalances and distortions than VOC schemes, constant switching frequency and almost sinusoidal output currents.

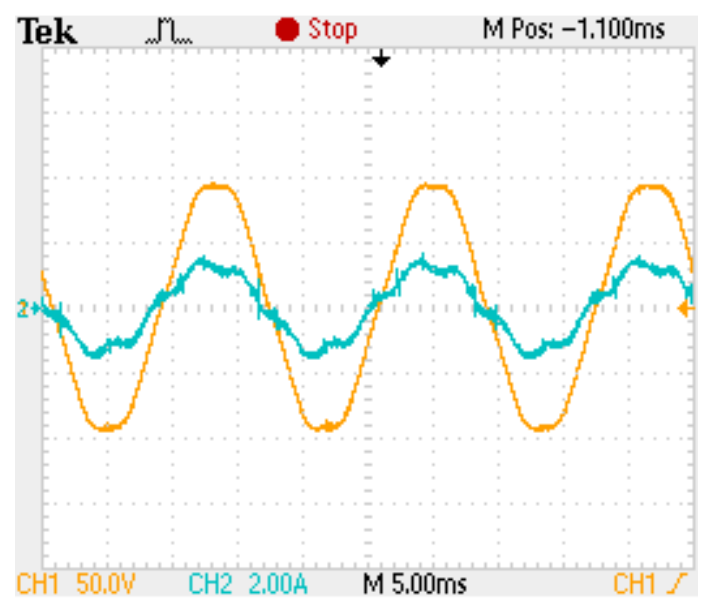

Fig. 11 Phase a grid voltage and filter current obtained using the VOC scheme.

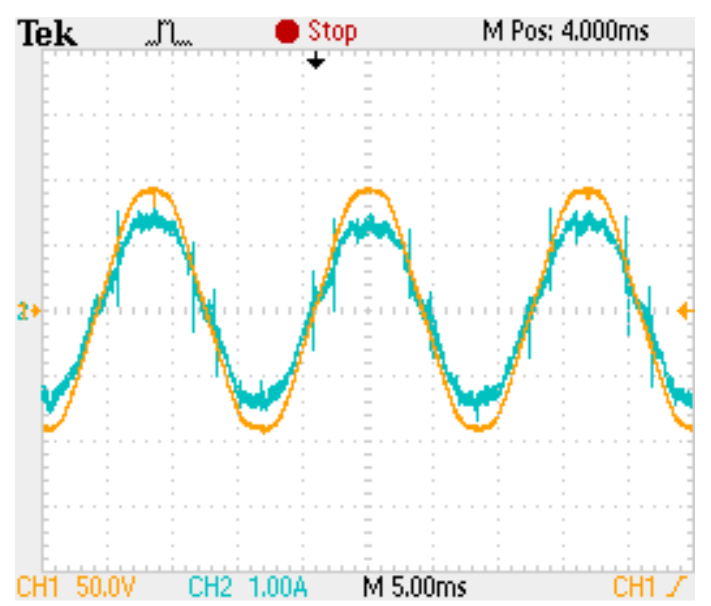

Fig. 12 Phase a grid voltage and filter current obtained using the SM-DPC scheme.

Robustness to parameter variations are guaranteed and a design example was considered for allowing variations in the filter inductance. Most characteristics of the proposed scheme were verified in the simulation and experimental results. It is worth mentioning that since no current control is used in DPC methods, a way of limiting the currents in an acceptable range is difficult task. Strategies for limiting the reference current in VOC rectifiers can be found in [20][21]. Similar work must be done for limiting current in DPC rectifiers.

\section{ACKNOWLEDGEMENT}

The authors of this paper are grateful to CAPES and $\mathrm{CNPq}$ for the financial support for this investigation.

\section{REFERENCES}

[1] D. C. Martins, A. H. de Oliveira and I. Barbi, "Retificador Trifásico Isolado com Correção do Fator de Potência Empregando o Conversor cc-cc Sepic em Condição Contínua," Eletrônica de Potência, vol. 6, no. 1, December, 2001.

[2] J. G. Marafão, J. A. Pomilio and G. Spiazzi, "Implementação e Controle de Retificador Trifásico de 
Alta Qualidade com Comutação em Baixa Frequência," Eletrônica de Potência, vol. 7, no. 1, November, 2002.

[3] F. J. M. de Seixas and I. Barbi, "Retificador Trifásico Isolado em Alta Frequância e com Baixa Distorção de Corrente na Rede," Eletrônica de Potência, vol. 7, no. 1, November, 2002.

[4] A. Chehab, J. Urbanetz Junior and I. Barbi, "Conversor Boost Acoplado à Saída de um Retificador Trifásico de 18kW Utilizando Transformador de Interfase de Linha," Eletrônica de Potência, vol. 9, no. 1, June, 2004.

[5] L.C. G. de Freitas, E. A. A. Coelho, M. G. Simões, C. A. Canesin and L. C. de Freitas, "Um Novo Retificador Trifásico Híbrido Multipulsos com Elevado Fator de Potência," Eletrônica de Potência, vol. 10, no. 2, November, 2005.

[6] J. O. Soares, C. A. Canesin, L. C. de Freitas and F. A. S. Gonçalves, "Retificador Trifásico Híbrido Operando com Controle Digital e Modulação por Histerese," Eletrônica de Potência, vol. 13, no. 4, November, 2008.

[7] J.W. Dixon, B.T. Ooi, "Indirect Current Control of a Unity Power Factor Sinusoidal Current Boost Type Three-Phase Rectifier", IEEE Trans. Industrial Electronics, vol. 35, no. 4, pp. 508-515, November 1988.

[8] T. Habetler and D. Divan, "Angle Controlled Current Regulated Rectifiers for AC_AC Converters", in Proc. of IEEE PESC, pp. 704-710, 1989.

[9] T. Noguchi, H. Tomiki, S. Kondo, and I. Takahashi, "Direct Power Control of PWM Converter Without Power-Source Voltage Sensors", IEEE Trans. Industry Applications, vol. 34, pp. 473-479, May-June 1998.

[10] T. Ohnishi, "Three-Phase PWM Converter/Inverter by Means of Instantaneous Active and Reactive power Control", in Proc. of IEEE IECON, pp. 819-824, 1991.

[11] M. Malinowski, M. Kazmierkowski, S. Hansen, F Blaabjerg, and G. Marques, "Virtual Flux Based Direct Power Control of Three-Phase PWM Rectifiers", IEEE Trans. Industry Applications, vol. 37, pp. 1019-1027, July-Aug. 2001.

[12] M. Malinowski, M. Jasinski and M. Kazmierkowski, "Simple Direct Power Control of Three-Phase PWM Rectifier Using Space-Vector Modulation" , IEEE Trans. Industrial Electronics, vol. 51, no. 2, pp. 447454, April 2004.

[13] M. Malinowski and M. Kamierkowski, "DSP Implementation of Direct Power Control with Constant Switching Frequency for Three-Phase PWM Rectifiers", in Proc. of IEEE IECON, pp. 819-824, 1991.

[14] G. Abad, M. Rodríguez and J. Poza, "Predictive Direct Power Control of the Doubly Fed Induction Machine with Reduced Power Ripple at Low Constant Switching Frequency", in Proc. of IEEE ISIE, pp. 1119-1124, 2007.

[15] T. Wei, "A Novel Direct Power Control Method of Three-Phase Active Rectifiers in Industrial Drive System", in Proc. of IEEE Intnl. Conf. on Mechatronics and Automation, pp. 3712-3716, 2007.

[16] W. Gao, Y. Wang and A. Homaifa, "Discrete-Time Variable Structure Control Systems", IEEE Trans.
Industrial Electronics, vol. 42, no. 2, pp. 117-122, April 1995.

[17] V. Kaura, and V. Blasko, "Operation of a phase locked loop system under distorted utility conditions," IEEE Trans. Ind. App., vol. 33, n. 1, Jan./Feb. 1997, pp. 58-63.

[18] L. Asiminoaei, F. Blaabjerg, and S. Hansen, "Detection is key - harmonic detection methods for active power filter applications," IEEE Ind. App. Magazine, vol.13, n. 4, pp. 22-33, July-Aug. 2007.

[19] P. Rodriguez, R. Teodorescu, I. Candela, A. Timbus, M. Liserre, and F. Blaabjerg, "New Positive-Sequence Voltage Detector for Grid Synchronization of Power Converters Under Faulty Grid Conditions," in Proc. of IEEE Power Electronics Specialists Conference PESC'06, pp. 1-7, June 2006.

[20] R. Ottersten and J. Svensson, "Vector Current Controlled Voltage Source Converter-Deadbeat Control and Saturation Strategies," IEEE Trans. Power Electronics, vol. 17, no. 2, March 2002.

[21] G. S. Azevedo; P. Rodriguez, M. Cavalcanti; G. Vazquez and F. Neves, "New Control Strategy to Allow Photovoltaic Systems Operation under Grid Faults," Congresso Brasileiro de Eletrônica de Potência COBEP, 2009.

\section{BIOGRAPHIES}

Francisco A. S. Neves was born in Campina Grande, Brazil, in 1963. He received the B.S. and M.Sc. degrees in electrical engineering from the Federal University of Pernambuco, Recife, Brazil, in 1984 and 1992, respectively, and the Ph.D. degree in electrical engineering from the Federal University of Minas Gerais, Belo Horizonte, Brazil, in 1999.

He worked as a visiting scholar at Georgia Institute of Technology - USA, during 1999, and at Alcala University Spain, from Feb/2008 to Jan/2009. Since 1993, he has been with the Department of Electrical Engineering, Federal University of Pernambuco, where he is currently a Professor of Electrical Engineering. His research interests include power electronics, renewable energy systems, power quality and grid synchronization methods.

Roberto Feliciano Dias Filho was born in Timbaúba, Brazil, in 1979. He received the B.S. degree in electrical engineering from State University of Pernambuco, Recife, Brazil, in 2003 and the M.S. degree in same area from the Federal University of Pernambuco, Recife, Brazil, in 2009. He works at CHESF, Brazilian federal electric power utility, on developing activities in power system protection field. His research interests are related to power converters control, grid synchronization and phasor estimation methods, wind generation themes and digital simulation of power systems.

Felipe C. Camboim was born in Recife, Brazil, in 1982 . $\mathrm{He}$ received the B.S. and the M.S. degrees in electrical engineering from the Federal University of Pernambuco, Recife, Brazil, in 2007 and 2009, respectively. His research interests are three-phase power converters and digital control.

Marcelo C. Cavalcanti was born in Recife, Brazil, in 1972. He received the B.S. degree in electrical engineering in 1997 from the Federal University of Pernambuco, Recife, Brazil, and the M.S. and Ph.D. degrees in electrical 
engineering from the Federal University of Campina Grande, Campina Grande, Brazil, in 1999 and 2003, respectively.

Since 2003, he has been at the Department of Electrical Engineering, Federal University of Pernambuco, where he is currently a Professor of Electrical Engineering. His research interests are renewable systems, power quality and threephase matrix converters.

Emilio J. Bueno was born in Madrid, Spain, in 1972. He received the M.S. and Ph.D. degrees in electronics engineering from the Universidad de Alcalá, Madrid, Spain, in 1999 and 2005, respectively.

$\mathrm{He}$ is currently an Associate Professor with the Department of Electronics, Universidad de Alcalá, where he is a member of the Research Group "Electronics Engineering Applied to the Renewable Energies." His research interests include power electronic systems, control of power electronic converters, power quality, and distributed power generation systems. 